\title{
Affect-focused psychodynamic psychotherapy for depression and anxiety through the Internet: a randomized controlled trial
}

Background: Psychodynamic psychotherapy is a psychological treatment approach that has a growing empirical base. Research has indicated an association between therapist-facilitated affective experience and outcome in psychodynamic therapy. Affect-phobia therapy (APT), as outlined by McCullough et al., is a psychodynamic treatment that emphasizes a strong focus on expression and experience of affect. This model has neither been evaluated for depression nor anxiety disorders in a randomized controlled trial. While Internet-delivered psychodynamic treatments for depression and generalized anxiety disorder exist, they have not been based on APT. The aim of this randomized controlled trial was to investigate the efficacy of an Internet-based, psychodynamic, guided self-help treatment based on APT for depression and anxiety disorders. Methods: One hundred participants with diagnoses of mood and anxiety disorders participated in a randomized (1:1 ratio) controlled trial of an active group versus a control condition. The treatment group received a 10-week, psychodynamic, guided self-help treatment based on APT that was delivered through the Internet. The treatment consisted of eight text-based treatment modules and included therapist contact (9.5 minutes per client and week, on average) in a secure online environment. Participants in the control group also received online therapist support and clinical monitoring of symptoms, but received no treatment modules. Outcome measures were the 9-item Patient Health Questionnaire Depression Scale (PHQ-9) and the 7-item Generalized Anxiety Disorder Scale (GAD-7). Process measures were also included. All measures were administered weekly during the treatment period and at a 7-month follow-up. Results: Mixed models analyses using the full intention-to-treat sample revealed significant interaction effects of group and time on all outcome measures, when comparing treatment to the control group. A large between-group effect size of Cohen's $d=0.77$ (95\% CI: $0.37-1.18$ ) was found on the PHQ-9 and a moderately large between-group effect size $d=0.48$ (95\% CI: $0.08-0.87)$ was found on the GAD-7. The number of patients who recovered (had no diagnoses of depression and anxiety, and had less than 10 on both the PHQ-9 and the GAD-7) were at post-treatment 52\% in the treatment group and 24\% in the control group. This difference was significant, $\mathrm{X} 2(\mathrm{~N}=100, \mathrm{df}=1)=8.3, \mathrm{p}<.01$. From 
post-treatment to follow-up, treatment gains were maintained on the PHQ-9, and significant improvements were seen on the GAD-7. Conslusion: This study provides initial support for the efficacy of Internet-delivered psychodynamic therapy based on the affect-phobia model in the treatment of depression and anxiety disorders. The results support the conclusion that psychodynamic treatment approaches may be transferred to the guided self-help format and delivered via the Internet. 
1 AUTHOR LIST:

2 Robert Johansson ${ }^{1 \S}$, Martin Björklund ${ }^{1}$, Christoffer Hornborg ${ }^{1}$, Stina Karlsson ${ }^{1}$, Hugo

3 Hesser ${ }^{1}$, Brjánn Ljótsson², Andréas Rousseau ${ }^{3}$, Ronald J. Frederick ${ }^{4}$, Gerhard

4 Andersson $^{1,5,6}$

5

6 'Department of Behavioural Sciences and Learning, Linköping University, Linköping,

7 Sweden

8 2Department of Clinical Neuroscience, Division of Psychology, Karolinska Institutet,

9 Sweden

$10{ }^{3}$ Psychiatric Clinic, University Hospital of Linköping, Linköping, Sweden

$11{ }^{4}$ Center for Courageous Living, Beverly Hills 90210, California, United States

$12{ }^{5}$ Department of Clinical Neuroscience, Psychiatry section, Karolinska Institutet,

13 Stockholm, Sweden

$14{ }^{6}$ Swedish Institute for Disability Research, Linköping University, Linköping, Sweden 15

$16{ }^{\S}$ Corresponding author

18 CORRESPONDING AUTHOR:

19 Robert Johansson

20 Department of Behavioural Sciences and Learning

21 Linköping University

22 SE-58183 Linköping

23 Sweden

24 Phone: +46 (0)13 282217

25 E-mail: robert.johansson@liu.se

PeerJ reviewing PDF | (v2013:05:525:1:1:NEW 20 Jun 2013) 


\section{Introduction}

2 The aim of this randomized controlled trial was to investigate the efficacy of an

3 Internet-delivered psychodynamic guided self-help treatment for depression and

4 anxiety disorders that was based on the affect-phobia model of psychopathology

5 (McCullough et al., 2003). The project extends previous research on

6 Internet-delivered psychological treatments in general, and that of Internet-delivered

7 psychodynamic psychotherapy in particular (Andersson et al., 2012; Johansson et al.,

8 2012). An overview of the trial can be seen in Figure 1.

10 Depression and anxiety disorders are major world-wide health problems, which lower

11 the quality of life for the individual and generate large costs for society (Ebmeier,

12 Donaghey, \& Steele, 2006; Smit et al., 2006). Lifetime prevalence for mood disorders

13 and anxiety disorders in the US have been estimated to be $20.8 \%$ and $28.8 \%$,

14 respectively (Kessler et al., 2005).

16 Psychodynamic psychotherapy is a psychological treatment approach that has a

17 growing empirical base (Town et al., 2012), with research support for e.g. depression

18 (Driessen et al., 2010), social anxiety disorder (Leichsenring et al., 2013), panic

19 disorder (Milrod et al., 2007), and generalized anxiety disorder (Leichsenring et al.,

20 2009). There is a variation among the psychodynamic therapies in the degree to which

21 they focus on expression and experience of affect. Diener, Hilsenroth, and

22 Weinberger (2007) conducted a meta-analysis of high-quality studies that had

23 examined the role of therapist focus on affect in psychodynamic psychotherapy. The

24 results indicated that the more therapists facilitated the affective

25 experience/expression in psychodynamic therapy, the more patients improved (Diener 
1 et al., 2007). Thus, keeping a focus on affect may be one way of enhancing

2 psychodynamic psychotherapies.

4 One psychodynamic treatment that has a strong focus on expression and experience of

5 affect is affect-phobia therapy (APT), developed by (McCullough et al., 2003). APT

6 follows a treatment model which adheres to the fundamental structure of

7 psychodynamic psychotherapy as outlined by Malan's triangle of conflict (i.e., the

8 experience/expression of feelings (F) is blocked by defenses (D) and anxieties (A))

9 and triangle of person (i.e., conflicted patterns began with past persons (P), are

10 maintained with current persons (C), and can be enacted with a therapist (T)), as

11 illustrated in Figure 2 (Malan, 1995). Typically in APT, the therapist clarifies a

12 client's defenses, helps the client to observe and experience the underlying affects,

13 and helps the client to regulate associated anxiety (McCullough et al., 2003).

14 Formally, the treatment includes three main treatment objectives: defense

15 restructuring (recognizing and relinquishing maladaptive defenses), affect

16 restructuring (desensitization of affects through exposure to conflicted feeling), and

17 self/other restructuring (improvement in sense of self and relationship with others).

18 The main goal of psychodynamic psychotherapy based on the APT model, is to help

19 clients experience and to adaptively express previously avoided feelings (McCullough

20 et al., 2003). That goal is shared with an entire set of psychodynamic psychotherapies

21 that are grouped under the umbrella term experiential dynamic therapies (Osimo \&

22 Stein, 2012), which in addition to APT includes, for example, Intensive Short-Term

23 Dynamic Psychotherapy (Abbass, Town, \& Driessen, 2012; Davanloo, 2000), and

24 Accelerated Experiential Dynamic Psychotherapy (Fosha, 2000). Two randomized

25 trials, investigating the efficacy of APT in the treatment of personality disorders, 
1 found that APT can be effective in reducing general psychiatric symptoms (Svartberg,

2 Stiles, \& Seltzer, 2004; Winston et al., 1994). However, except for case-series and

3 some small uncontrolled studies (e.g., Dornelas, Ferrand, Stepnowski, Barbagallo, \&

4 McCullough, 2010), to date no trial has investigated the efficacy of APT for patients

5 with a principal Axis I disorder.

6

7 During the last decade, numerous trials on guided self-help and Internet-delivered

8 cognitive behavior therapy (CBT) for various psychiatric disorders have been

9 conducted (Andersson, 2009; Hedman, Ljótsson, \& Lindefors, 2012; Johansson \&

10 Andersson, 2012). For mild to moderate depression and anxiety disorders, it seems

11 safe to conclude that these treatments are as effective as face-to-face treatments

12 (Cuijpers, Donker, Van Straten, Li, \& Andersson, 2010). While most research

13 regarding Internet-based psychological treatments have concerned CBT, there are

14 exceptions. Results from two recent randomized controlled trials focusing on the

15 treatment of depression and generalized anxiety disorder indicate that also

16 psychodynamic treatments can be delivered via the Internet (Andersson et al., 2012;

17 Johansson et al., 2012).

19 This randomized controlled trial aimed to examine the effects of an Internet-delivered

20 psychodynamic treatment, based on the affect-phobia model of psychopathology.

21 Participants had depression and anxiety disorders. The treatment was given as

22 self-help with additional therapist support via the Internet, and compared to a control

23 group who also received online support. As compared with the control condition, a

24 significant effect of treatment was expected both on measures of depression and

25 anxiety for the full sample. In addition, a larger effect was expected on measures of 
1 depression for participants with depression as their main presenting problem as

2 compared with those who did not have this as the main problem. Similar, a larger

3 effect on anxiety measures was expected for participants with a principal anxiety

4 diagnosis as compared with those who did not have such a diagnosis. We also

5 investigated the uncontrolled effects of the treatment 7 months following the

6 completion of the treatment.

\section{Materials \& Methods}

9 This study is reported in accordance with the CONSORT statement for clinical trials

10 (Schulz, Altman, \& Moher, 2010). Clinicaltrials.gov registration ID is NCT01532219.

11 This study received approval from the Regional Ethics Board of Linköping, Sweden

12 (Approval number: 2011/400-31). Written informed consent was obtained from all

13 participants via the online treatment platform. Participants received the treatment at

14 no cost. After being enrolled in the study, all participants were assigned one of the

15 therapists as their personal contact. Half of the participants received psychodynamic

16 treatment in the format of guided self-help and the other half was assigned to a

17 waiting-list where participants also received support via the Internet. The waiting-list

18 served as the control group.

\section{Participants}

20 Patients were recruited via the Internet and advertisements in newspapers during

21 January 2012. The final follow-up evaluation occurred in December 2012. Patients

22 were eligible for participation if they 1) had at least one of the following Axis-I

23 diagnoses, specified by DSM-IV criteria: Major depressive disorder, social anxiety

24 disorder, panic disorder, generalized anxiety disorder, depressive and/or anxiety

25 disorder not otherwise specified; 2) had a raw score of at least 10 on either the 9-item 
1 Patient Health Questionnaire Depression Scale (PHQ-9; Kroenke, Spitzer, \&

2 Williams, 2001) or the 7-item Generalized Anxiety Disorder Scale (GAD-7; Spitzer,

3 Kroenke, Williams, \& Löwe, 2006); 3) had no assessed risk of suicidality; 4) had no

4 concurrent psychological treatment that potentially could interfere with the treatment

5 tested; 5) if on psychotropic medication, this treatment had to be stable for three

6 months; 6) did not have other primary disorders that needed different treatments or

7 that could be affected negatively by the treatment; 7) had no alcohol or drug abuse; 8)

8 were at least 18 years old.

\section{Randomization and procedure}

10 After initial application, participants were invited to an online screening which

11 consisted of demographic questions and online versions of the outcome measures (see

12 below). These results were later used as a pre-treatment assessment. If initial inclusion

13 criteria were met (having more than 10 on the PHQ-9 or the GAD-7), participants

14 were contacted for a telephone-based diagnostic interview, based on the

15 Mini-International Neuropsychiatric Interview (MINI; Sheehan et al., 1998). This

16 procedure is described further below. After confirming additional inclusion criteria,

17 participants were randomized to either treatment or waiting-list (1:1 ratio; block

18 randomization), using an online randomization tool. An independent person, not

19 otherwise involved in the study, handled the randomization. The procedure is

20 illustrated in the CONSORT flowchart in Figure 1.

\section{Intervention}

23 The treatment lasted for 10 weeks and consisted of eight self-help modules given with

24 text-based therapist support. A secure online environment was used both for the

25 delivery of self-help material and for communication with the therapists. Therapist 
1 support was given asynchronously, i.e. similarly to e-mail. The primary role of the

2 therapists was to give feedback on completed modules and administer gradual access

3 to the treatment. In general, feedback was given on Mondays, but the therapists were

4 available to answer additional questions within 24 hours.

5

6 The self-help modules were based on the book 'Living Like You Mean It' by Ronald

7 J. Frederick (Frederick, 2009) that follows a similar structure as the original

8 affect-phobia treatment manual. Throughout treatment, participants were taught how

9 to practice "emotional mindfulness" as a way of identifying, attending to, and being

10 present with emotional experience. The treatment aimed to teach clients to gradually

11 develop mindful presence as a response to the physical manifestation of emotions

12 which, within the APT model, can be considered as exposure to one's feelings.

13 Throughout the treatment modules, the affect-phobia model as illustrated by the

14 conflict triangle (Figure 2) was presented to illustrate the function of interventions and

15 to clarify patient case stories. This included techniques to identify and relinquish

16 maladaptive defenses (D), regulate anxiety (A), and approach and experience warded

17 off feelings (F). The final part of the manual contained material on how to make use

18 of experiencing one's core feelings, for example, to express these feelings in

19 interpersonal contexts. In the APT model, expressing feelings to others is seen as

20 essential to shifting both the sense of self and others (McCullough et al., 2003). All

21 modules contained homework exercises that needed to be completed before

22 proceeding to the next module. The chapter structure of the manual was: 1)

23 Introduction and problem formulation using the affect-phobia model; 2) Historical

24 understanding and explanation of the problem described; 3) Mindfulness practice to

25 start approaching emotional experience; 4) Defense restructuring; 5) Anxiety 
1 regulation techniques; 6) Affect experiencing techniques; 7) Affect expression and

2 self/other restructuring; 8) A summary of the previous material and advice for

3 continued work. Further details on the treatment can be found in the original treatment

4 manual (Frederick, 2009).

\section{Control group}

6 For ethical reasons, participants on waiting-list also had continuous contact with an

7 assigned therapist during the same 10-week period. Every Monday, therapists were

8 scheduled to initiate contact with the participants, using the same secure online

9 environment as used with the treatment group. Contact involved clinical monitoring

10 of symptoms and questions typically regarding clients' experiences from the previous

11 week. Therapists were instructed to give basic support, but not to use any specific

12 psychological techniques other than empathic listening and asking further questions.

13 As the control group did not work with any treatment modules, the therapists were

14 expected to spend less time with the participants from this group. After the treatment

15 period had ended, participants from the control group were offered an 8-week version

16 of the treatment. The results from that treatment period are, however, outside the

17 scope of this study.

\section{Outcome measures}

19 The main effect of treatment was assessed using two measures regarding symptoms of

20 depression and anxiety. Depression severity was assessed with the PHQ-9 (Kroenke et

21 al., 2001), a self-report measure which consists of nine items, each scored 0 -3, with a

22 total score ranging from 0 to 27. The PHQ-9 has good psychometric properties,

23 including an internal consistency in the range Cronbach’s $\alpha=.86-.89$ and a

24 test-retest reliability of $r=.84$ (Kroenke, Spitzer, Williams, \& Löwe, 2010). Several

25 studies have established that the PHQ-9 is sensitive to change during treatment 
1 (Kroenke et al., 2010). In addition, the PHQ-9 performs similarly regardless of the

2 mode of operation (e.g., as traditional pen and paper, or touch-screen computer; Fann

3 et al., 2009). Anxiety severity was measured by the GAD-7 (Spitzer et al., 2006), a

4 self-rated 7-item measure, also with items scored 0-3, and with a total score of 21.

5 Internal consistency is excellent (Cronbach's $\alpha=.92$ ) and with a good test-retest

6 reliability of $r=.83$. Convergent validity of the GAD-7 has been shown to be good, as

7 demonstrated by its correlations with the Beck Anxiety Inventory $(r=.72)$ and the

8 anxiety dimension of SCL-90 ( $r=$.74) (Kroenke et al., 2010). Both measures were

9 administered pre-treatment, weekly during treatment, post-treatment and at the

10 7-month follow-up.

\section{Process measures}

12 Two measures were included to assess two processes assumed to be relevant during

13 treatment. Both measures were administered pre-treatment, weekly during treatment,

14 post-treatment and at follow-up. The Emotional Processing Scale (EPS-25; Baker et

15 al., 2010) was used to assess emotional processing deficits and the process of

16 emotional change during treatment. In addition, the Swedish 29-item version (Lilja et

17 al., 2011) of the Five Facets of Mindfulness Questionnaire (FFMQ; Baer, Smith,

18 Hopkins, Krietemeyer, \& Toney, 2006) was included to measure the influence of

19 general mindfulness skills. Psychometric properties have been found to be strong for

20 the EPS-25 (Cronbach's $\alpha=0.92$ ) (Baker et al., 2010) and good for the Swedish

21 29-item FFMQ (Cronbach's $\alpha=0.81$ ) (Lilja et al., 2011). The change in total scores

22 on these measures were assumed to reflect an overall change in these processes. A

23 detailed analysis of how these processes were related to treatment outcome will be

24 reported in a separate paper. 


\section{Clinician-administered measures}

2 DSM-IV diagnoses, including a participant's principal diagnosis, were recorded using

3 the MINI Interview (Sheehan et al., 1998). This instrument is completely structured,

4 making it suitable for less experienced assessors (Sheehan et al., 1998). DSM-IV

5 diagnoses recorded at pre-treatment were followed up at post-treatment and at the

6 7-month follow-up. The interviewers were blind to treatment condition at

7 post-treatment. Another structured interview was administered at post-treatment and

8 at follow-up, which aimed to give an estimation of global improvement, measured by

9 the 7-point version of the Clinical Global Impression - Improvement (CGI-I) scale

10 (Guy, 1976). All interviews were conducted by master's level final-year clinical

11 psychologist students who were explicitly trained in the diagnostic procedure. A

12 licensed psychologist with a thorough experience from conducting diagnostic

13 interviews provided supervision throughout the assessment period and a psychiatrist

14 was available for additional consultation.

\section{Therapist training and supervision}

16 The therapists were three master's level students in their last semester of a 5-year

17 clinical psychologist program. All therapists have had clinical training in

18 affect-focused psychodynamic psychotherapy and had clinical experience from

19 working with this kind of psychotherapy. Prior to the study, all therapists were also

20 trained in providing guided self-help treatments via the Internet. Throughout the trial,

21 clinical supervision was provided by psychologist Ronald J. Frederick, who had

22 authored the original treatment manual. Treatment integrity and adherence to the

23 treatment manual were monitored during supervision. 


\section{Subgroups based on depression and anxiety symptomatology}

2 To investigate differential efficacy between participants who had either depression or

3 anxiety as their main presenting problem, all participants were classified based on

4 their main symptomatology. The classification was based on the assessment of a

5 participant's principal diagnosis that was recorded in the diagnostic interview

6 conducted at baseline. These categories were used to assess whether the treatment was

7 more effective in treating depressive symptoms among participants with principal

8 depression, and analogously regarding anxiety.

\section{Statistical analyses}

10 Pre-treatment group differences in demographics and on the outcome measures were

11 tested using $X^{2}$-tests (for categorical variables) and independent $t$-tests (for continuous

12 variables). Normality was confirmed by the Shapiro-Wilk test (Shapiro \& Wilk, 1965)

13 in conjunction with plots of the distribution of data. No significant departure from

14 normality was detected. Mixed-effects models for repeated-measures data, fitted with

15 maximum likelihood estimation, was used for all continuous outcomes (Verbeke \&

16 Molenberghs, 2000). Mixed models takes into account all available data from all

17 randomized participants, making it a full intention-to-treat analysis, provides unbiased

18 estimates in the presence of missing data under a fairly unrestrictive missing

19 assumption (i.e., missing at random), and adequately handles nested data structures

20 inherent in repeated-measures data (Gueorguieva \& Krystal, 2004; Mallinckrodt,

21 Clark, \& David, 2001). All models included random intercepts and slopes, with

22 group, linear time and their interaction included as fixed predictors. Time was

23 considered as a continuous variable and therefore entered as a covariate in the model.

24 For each of the four outcome measures, difference in efficacy between the treatment

25 and the control group were investigated by examining the fixed interaction term of 
1 group and linear time. To account for the multiple comparisons, statistical

2 significance was determined using a Bonferroni corrected alpha of 0.0125. Subgroup

3 differences in efficacy were investigated using a fixed three-way interaction term of

4 group, subgroup and time.

5

6 Recovery after treatment was defined as having a score less than 10 on both the

7 PHQ-9 and the GAD-7, and not fulfilling criteria for any DSM-IV diagnosis. The

8 same definition was used at follow-up. Between-group differences in recovery at

9 post-treatment were investigated using $X^{2}$-tests. To handle missing data from

10 follow-up diagnostic interviews and estimates of global improvement, post-treatment

11 data were carried forward to the follow-up.

12

13 Sample size was determined a priori based on power analyses. These power

14 calculations were based on a linear mixed-effects model (10 time points with an

15 autoregressive error structure with a random intercept and slope), an alpha set at 0.05,

16 power set at 0.80 , a predicted effect size of Cohen's $d=0.50$ and the potential for $10 \%$

17 total attrition rate (at equal rate across time and condition). That analysis suggested

18 that 51.3 participants per group were needed to obtain the desired effect.

20 Within- and between-group effect sizes (Cohen's $d$ ) were calculated by dividing the

21 differences in means by the pooled standard deviations (Borenstein, Hedges, Higgins,

22 \& Rothstein, 2009). Following Cohen's guidelines a between-group effect size in the

23 range of $0.20-0.49$ is small, $0.50-0.79$ is moderate, and an effect size of 0.80 and

24 above is large (Cohen, 1988).

25 


\section{Results}

\section{Enrollment and baseline characteristics}

3 One hundred individuals with depression and/or anxiety disorders were enrolled in the

4 study. There were no significant pre-treatment mean differences between the

5 treatment group and the control group on any outcome measures (all $t$ 's $<0.97$, all $p$ 's

$6>$.33). Additionally, there were no significant differences between the groups on any

7 demographic data or current/past treatment with medication and/or psychological

8 treatment. A complete description of demographic data of included participants is

9 available in Table 1.

13 Regarding subgroups of principal depression and anxiety, there was a difference

14 between subgroups in the number of participants in an acute episode of depression,

$15 \chi^{2}(N=100, d f=1)=39.4, p<.001$, with 55/57 (96.5\%; two participants had

16 depression not otherwise specified) compared to 17/43 (39.5\%) for subgroups of

17 depression and anxiety, respectively. Similarly, there were significantly more

18 participants with a principal anxiety disorder that had GAD (67.4\%) compared to

$1935.1 \%$ from the depression subgroup, $\chi^{2}(N=100, d f=1)=10.3, p<.001$. There were

20 no differences between subgroups regarding diagnoses of panic disorder and social

21 phobia. Also, there were no differences in any demographics. However, there was a

22 significant difference between subgroups in depression severity as measured by the

23 PHQ-9 at baseline, $t(98)=3.70, p<.001$. However, no significant baseline difference

24 on the GAD-7 was found $t(98)=1.23, p=.22$. 


\section{Attrition and adherence}

2 At post-treatment, $100 \%$ of the data was collected. At the 7-month follow-up, 47/50

3 (94\%) of the self-report measures and 40/50 (80\%) of the data from the follow-up

4 interviews (i.e., diagnostic data and estimates of global improvement) were collected.

5 Adherence to treatment was defined as the number of modules completed. A module

6 was only considered completed if the homework assignment had been sent to the

7 therapist. Out of the 50 participants receiving treatment, 42 (84\%) completed all

8 modules. Only 4 participants (8\%) completed less than half of the program.

\section{Outcome and process measures}

10 Means, standard deviations and effect sizes within and between groups for the

11 self-report measures are presented in Table 2 and Table 3. Both the treatment group

12 and the control group had substantial within-group effects after the 10-week period.

13 Mixed models analyses revealed significant interaction effects of treatment group and

14 time on the PHQ-9, $F(1,102.1)=19.94, p<.001$, and the GAD-7, $F(1,105.1)=7.86$,

$15 p<.01$. Both interaction effects were significant at the Bonferroni-corrected alpha

16 level of $p<.0125$. Estimates of fixed effects for the PHQ-9 and the GAD-7 were as

17 follows. Intercept: 12.37 and 10.71 ( $p^{\prime}$ s < .001); Group: 0.11 and 0.14 ( $p$ 's > .85);

18 Time: -0.64 and -0.49 ( $p$ 's < .001); Group $\times$ Time: 0.40 and $0.23\left(p^{\prime}\right.$ s $\left.<.01\right)$. Random

19 effects for the PHQ-9 and the GAD-7 were estimated as follows. Intercept: 14.33 and

2012.78 ( $p$ 's < .001); Time: 0.15 and 0.12 ( $p$ 's < .001). Between-group effect sizes at

21 post-treatment was large $(d=0.77)$ for depression and moderate $(d=0.48)$ for

22 anxiety, favoring treatment over control. The continuous within-group changes on the

23 PHQ-9 and the GAD-7 are illustrated in Figure 3. At the 7-month follow-up, the

24 treatment effect was stable. Paired $t$-tests conducted post hoc showed that there were

25 significant post-treatment versus follow-up decrease on the GAD-7, $t(46)=2.03, p<$. 
105 , and a trend towards a significant decrease on the PHQ-9, $t(46)=1.42, p=.16$. For

2 the EPS-25 and the FFMQ, there were also significant interaction effects of treatment

3 group and time $(F(1,104.5)=26.5$ and $F(1,101.2)=29.9$, respectively; Both $p$ 's $<$.

4 001). Both these interaction effects were significant at the Bonferroni-corrected alpha

5 level of $p<.0125$. Fixed effects for the EPS-25 and the FFMQ were estimated as

6 follows. Intercept: 4.70 and 72.76 ( $p$ 's < .001); Group: -0.16 and 3.67 ( $p$ 's > .15);

7 Time: -0.18 and 1.39 ( $p$ 's < .001); Group $\times$ Time: 0.13 and $-1.17\left(p^{\prime}\right.$ s $\left.<.001\right)$.

8 Estimates of random effects for the EPS-25 and the FFMQ were as follows. Intercept:

91.25 and 156.37 ( $p$ 's $<.001)$; Time: 0.013 and $0.98\left(p^{\prime}\right.$ s $\left.<.001\right)$. The between-group

10 effect at post-treatment was large for the EPS-25 $(d=0.82)$ and moderate to large $(d=$ 11 0.65) for the FFMQ.

--INSERT TABLE 3--

\section{Diagnoses}

17 The number of diagnoses among participants at pre-treatment, post-treatment and at

18 the 7-month follow-up are illustrated in Table 4. At post-treatment, there were

19 significantly fewer participants with a diagnosis of major depression in the treatment

20 group (10\%) than in the control group (32\%). The difference was significant $\left(\chi^{2}(N=\right.$

$21100, d f=1)=7.3, p<.01$ ). Reductions in the number of diagnoses of GAD, SP or PD

22 were not significantly different between groups at post-treatment.

\section{Recovery after treatment and clinical global improvement}

24 Categorical rates of recovery after treatment (i.e., a participant who did not fulfill

25 criteria for any DSM-IV diagnosis and reached a score less than 10 on both the 
1 PHQ-9 and the GAD-7) were significantly different at post-treatment between the

2 treatment group $(n=26 ; 52.0 \%)$ and the control group $(n=12 ; 24.0 \%), \chi^{2}(N=100, d f$

$3=1)=8.3, p<.01$. At follow-up there were 25 participants (50.0\%) from the

4 treatment group who met the criteria for recovery.

5

6 Post-treatment interviews resulted in estimates of clinical global improvement

7 according to the CGI-I (Guy, 1976). In the treatment group, 28 participants (56.0\%)

8 were much or very much improved while this was only true for $11(22.0 \%)$ in the

9 control group. This difference was significant, $\chi^{2}(N=100, d f=1)=12.1, p<.001$. At

10 follow-up, this figure was 52\% $(n=26)$ in the treatment group.

\section{Subgroups of principal depression and anxiety}

12 There were no significant interaction effect of group, subgroup and time on neither

13 the PHQ-9 nor the GAD-7. This was despite the fact that the treatment had a very

14 large within-group group effect $(d=3.10)$ on the PHQ-9 in the depression subgroup,

15 compared to for those in the anxiety subgroup $(d=1.12)$. Thus, there were no

16 indications that the treatment was more effective in reducing symptoms of depression

17 among participants with a principal diagnosis of depression, or analogously for

18 anxiety symptoms.

\section{Therapist time}

20 In the treatment group, the average therapist time per client and week was 9.5 minutes

$21(S D=4.0)$. While there was a significant difference in average therapist time per

22 week between therapists $(F(2,47)=7.73, p<.001)$, there were no correlations

23 between therapist time and change scores on any of the outcome measures (all $r$ 's $<$.

24 19, all $p$ 's $>$.18). The average therapist time per client and week was 2.3 minutes (SD 
$1=0.86)$ in the control group. As expected, therapist time was significantly less in the

2 control group than in the treatment group, $t(98)=12.4, p<.001$.

\section{Participants' evaluation of the treatment}

4 Most participants were satisfied (46\%) or very satisfied (36\%) with the overall

5 treatment they had received. Nine (18\%) were indifferent or mildly dissatisfied, and

6 no one was clearly dissatisfied. An absolute majority (82\%) thought that the amount

7 of text was appropriate. A similar amount of participants considered the text

8 interesting and relevant, all the time (46\%) or most of the time (40\%). Most

9 participants considered the treatment to be very demanding (28\%), demanding (42\%)

10 or somewhat demanding (26\%). Importantly though, a majority considered the

11 treatment very much worth the effort (52\%) or worth the effort (38\%).

\section{Discussion}

14 This randomized controlled trial aimed to evaluate the effects of affect-phobia therapy

15 in the format of guided self-help through the Internet in a sample of participants with

16 depression and anxiety disorders. The results indicated that the treatment was

17 effective in reducing symptoms of depression and anxiety, and also in facilitating

18 emotional processing and mindfulness skills. Subgroup analyses gave no indications

19 of differential efficacy between participants with a principal diagnosis of depression

20 and those with principal anxiety. Treatment gains were maintained in the 7-month

21 follow-up.

23 The treatment manual used in this study aimed to implement a psychodynamic

24 treatment based on the affect-phobia model in self-help format. This approach calls

25 for a discussion on similarities and differences to the original APT manual. An 
1 assumption of this implementation was that the core principles of affect-phobia

2 treatment manual could be retained. This included the general model of

3 psychopathology (i.e., as illustrated by the triangle of conflict in Figure 2) and the

4 overall structure of the therapy. While the treatment emphasized how affect-phobic

5 patterns in a person's current life $(\mathrm{C})$ began with past persons (P), as illustrated in

6 Malan's triangle of person, the treatment did not address how these patterns could

7 potentially be enacted with the therapist (T). Importantly, these patterns were not

8 regarded as non-existing, but rather the treatment material did not address them nor

9 was it part of the role of the therapists to address these patterns. While the therapist

10 role might overlap between guided self-help and face-to-face therapy in several

11 aspects (Paxling et al., 2013), there is a difference in the present study in how the

12 treatment material taught "emotional mindfulness" as a way of conducting exposure

13 to one's feelings without the therapist being present. Some authors have suggested that

14 exposure with response prevention may result in better effects of treatment when

15 patients conduct the exposure by themselves, in their natural environment (Röper \&

16 Rachman, 1976; Salkovskis, 1985). If this is the case also in affect-phobia therapy and

17 how that would affect outcome is a question for further research, but it is possible that

18 self-exposure to feelings is at least as effective as exposure with a therapist present.

19 Importantly, as exposure with response prevention is assumed to be an active

20 mechanism in the treatment tested in this study, this would imply similarities in

21 working mechanisms in affect-focused psychodynamic treatment and cognitive

22 behavioral therapy based on principles of exposure. Similarly, several contemporary

23 CBT treatments have components of emotion regulation techniques (e.g., Berking,

24 Ebert, Cuijpers, \& Hofmann, 2013; Bryant et al., 2013), that seem overlapping to

25 affect-phobia treatment. Future research should investigate further similarities and 
1 differences between affect-focused psychodynamic therapy and various CBT models.

2 Summing up, despite the aforementioned differences to the original APT manual, we

3 believe that the manual used in the current study is indeed a valid implementation of a

4 psychodynamic therapy based on the affect-phobia model.

5

6 In affect-phobia therapy, the model of psychopathology is the same across disorders,

7 i.e. the triangle of conflict is assumed to explain both etiology and maintenance of for

8 example depression and anxiety disorders (McCullough et al., 2003). This aim is

9 similar to transdiagnostic and unified protocols where the treatment material has been

10 arranged to fit a broader range of patients (Barlow, Allen, \& Choate, 2004; Craske,

11 2012). Hence, affect-phobia therapy could be described as a transdiagnostic treatment.

12 While there are several studies on the efficacy of cognitive behavioral transdiagnostic

13 treatments for anxiety disorders (Farchione et al., 2012; McEvoy, Nathan, \& Norton,

14 2009), few exist that explicitly target both depression and anxiety. However, one

15 uncontrolled trial testing the effectiveness of a group-based intervention (McEvoy \&

16 Nathan, 2007) resulted in promising outcomes and showed comparable efficacy to

17 several disorder-specific treatments. More recently, Titov et al. (2011) provided

18 evidence of the efficacy of an Internet-delivered transdiagnostic program that targeted

19 both anxiety and depression, when compared to a waiting-list. Both these treatments

20 yielded within-group effect sizes of Cohen's $d$ around 1.0 for measures of depression

21 and anxiety. Hence, the affect-phobia treatment tested in this study, seems to stand

22 well when compared to other transdiagnostic treatments tested.

24 There are methodological limitations that need to be considered. First, as we recruited

25 participants from the community and not from for example a treatment clinic, the 
1 external validity of the findings are challenging to interpret. While there are studies on

2 ICBT that suggests generalizability to clinical settings (e.g., Bergström et al., 2010;

3 Hedman et al., 2013), this has yet to be proven for Internet-delivered psychodynamic

4 therapy. Moreover, more than half of the participants in the present study had three

5 years or more of university education. While this factor might have biased the results,

6 the average severity of depression and anxiety symptoms was moderate to moderately

7 severe (Kroenke et al., 2010), and more than half of the participants had comorbid

8 disorders, suggesting clinical representativity (Kessler, Merikangas, \& Wang, 2007).

9 A second methodological limitation concerns the substantial within-group effects in

10 the control group, that make the results harder to interpret. These effects are probably

11 due to the weekly clinical monitoring and supportive contact with the therapists in

12 addition to the extensive test procedures such as telephone interviews before and after

13 the treatment period. While these aspects might have biased the results, it also

14 highlights the need for research regarding specific factors in guided self-help

15 treatments. A third limitation concerns how missing data were handled at the 7-month

16 follow-up for the categorical measure of recovery. For that measure, missing data at

17 follow-up were replaced by that from post-treatment. When using that approach in

18 longitudinal analysis, there is a known risk for estimation bias (Gueorguieva \&

19 Krystal, 2004). While we did not compare the recovery rates over time (i.e., did not

20 include this measure in any longitudinal analysis) we still acknowledge that some

21 method of multiple imputation could have been used to account for the missing data

22 (Graham, 2009). Another limitation concerns the subgroup analyses. As the total

23 sample size was appropriate for the comparison between treatment and control, it

24 seem not to have been adequate for the analyses regarding subgroups of principal

25 depression and anxiety. This implies that a larger sample size would be needed in 
1 future research if investigating the effect of a transdiagnostic treatment on specific

2 diagnoses in a sample with multiple disorders. A related limitation concerns the

3 definition of the subgroups in this study. The group with principal anxiety disorders is

4 a heterogeneous group, e.g. in the sence that it includes both fear disorders (e.g. panic

5 disorder) and worry disorders (GAD). This may have confounded the subgroup

6 analyses. A final limitation that needs to be addressed concerns the therapists in the

7 study who all of whom were psychologists in training, albeit during the last semester

8 of training in a five year program and under regular supervision. It is possible that

9 more experienced therapists would have enabled even larger treatment effects. A

10 related concern is that psychologists in training conducted all diagnostic interviews.

11 While the psychologists were explicitly trained in the diagnostic procedures and

12 received supervision, there is a possibility that level of experience may have affected

13 how the diagnostic categories were defined. Importantly though, the MINI interview

14 has been designed to be administered by non-experts.

\section{Conclusions}

17 This study provides preliminary support for the efficacy of Internet-delivered

18 psychodynamic treatment based on the affect-phobia model in the treatment of

19 depression and anxiety disorders. This study provides further evidence that

20 psychodynamic treatment approaches may be transferred to the guided self-help

21 format and delivered via the Internet. Hence, this study adds to the empirical base of

22 Internet-delivered psychological treatments and to that of psychodynamic

23 psychotherapy in general. Finally, as we have no reason to believe that the treatment

24 would perform less effectively in a face-to-face setting, the findings from this study

25 call for further research on affect-focused psychotherapies. 


\section{Acknowledgements}

3 We would like to thank Frida Forsman, Linda Karlgren and Anton Sandell for

4 conducting diagnostic interviews at post-treatment and at follow-up, and in addition

5 acted as therapists when providing treatment to the control group. Additional thanks

6 to Maximilian Rubinsztein for conducting pre-treatment interviews and to Peter

7 Lilliengren for valuable comments on the manuscript. We would also like to thank Per

8 Carlbring for help during the recruitment phase and Alexander Alasjö for technical

9 support. We also thank Linköping University for funding and the Internet psychiatry

10 unit in Stockholm, Sweden for the use of the treatment platform. Finally, we would

11 also like to acknowledge the participants for their involvement and helpful comments.

\section{References}

13 Abbass, A., Town, J., \& Driessen, E. (2012). Intensive short-term dynamic psychotherapy: a systematic review and meta-analysis of outcome research. Harvard review of psychiatry, 20, 97-108.

Andersson, G. (2009). Using the Internet to provide cognitive behaviour therapy. Behaviour research and therapy, 47, 175-80.

18 Andersson, G., Paxling, B., Roch-Norlund, P., Östman, G., Norgren, A., Almlöv, J.,

19 Georén, L., Breitholtz, E., Dahlin, M., Cuijpers, P., Carlbring, P., \& Silverberg,

20 F. (2012). Internet-based psychodynamic vs. cognitive behavioural guided

21 self-help for generalized anxiety disorder: A randomised controlled trial.

22 Psychotherapy and psychosomatics, 81, 344-355. 
1 Baer, R. A., Smith, G. T., Hopkins, J., Krietemeyer, J., \& Toney, L. (2006). Using self-report assessment methods to explore facets of mindfulness. Assessment, 13, 27-45.

4 Baker, R., Thomas, S., Thomas, P. W., Gower, P., Santonastaso, M., \& Whittlesea, A. 5 (2010). The Emotional Processing Scale: scale refinement and abridgement 6 (EPS-25). Journal of psychosomatic research, 68, 83-8.

7 Barlow, D. H., Allen, L. B., \& Choate, M. L. (2004). Toward a unified treatment for emotional disorders. Behavior Therapy, 35, 205-230.

9 Bergström, J., Andersson, G., Ljótsson, B., Rück, C., Andréewitch, S., Karlsson, A., Carlbring, P., Andersson, E., \& Lindefors, N. (2010). Internet-versus group-administered cognitive behaviour therapy for panic disorder in a psychiatric setting: a randomised trial. BMC psychiatry, 10, 54.

13 Berking, M., Ebert, D., Cuijpers, P., \& Hofmann, S. G. (2013). Emotion Regulation 14 Skills Training Enhances the Efficacy of Inpatient Cognitive Behavioral Therapy for Major Depressive Disorder: A Randomized Controlled Trial. Psychotherapy

17 Borenstein, M., Hedges, L. V., Higgins, J. P. T., \& Rothstein, H. R. (2009). Introduction to Meta-Analysis. John Wiley \& Sons.

19 Bryant, R. A., Mastrodomenico, J., Hopwood, S., Kenny, L., Cahill, C., Kandris, E., 20 \& Taylor, K. (2013). Augmenting cognitive behaviour therapy for post-traumatic 21 stress disorder with emotion tolerance training: a randomized controlled trial. $22 \quad$ Psychological medicine, 1-8.

23 Cohen, J. (1988). Statistical power analysis for the behavioral sciences (2nd ed.).

24 Hillsdale, N.J.: Lawrence Erlbaum Associates. 
1 Craske, M. G. (2012). Transdiagnostic treatment for anxiety and depression. Depression and anxiety, 29, 749-53.

3 Cuijpers, P., Donker, T., Van Straten, A., Li, J., \& Andersson, G. (2010). Is guided 4 self-help as effective as face-to-face psychotherapy for depression and anxiety 5 disorders? A systematic review and meta-analysis of comparative outcome $6 \quad$ studies. Psychological medicine, 40, 1943-57.

7 Davanloo, H. (2000). Intensive short-term dynamic psychotherapy: selected papers of Habib Davanloo. Chichester: Wiley.

9 Diener, M. J., Hilsenroth, M. J., \& Weinberger, J. (2007). Therapist affect focus and patient outcomes in psychodynamic psychotherapy: a meta-analysis. The American journal of psychiatry, 164, 936-41.

12 Dornelas, E., Ferrand, J., Stepnowski, R., Barbagallo, J., \& McCullough, L. (2010). A 13 pilot study of affect-focused psychotherapy for antepartum depression. Journal of psychotherapy integration, 20, 364-382.

Driessen, E., Cuijpers, P., De Maat, S. C. M., Abbass, A., De Jonghe, F., \& Dekker, J. J. M. (2010). The efficacy of short-term psychodynamic psychotherapy for depression: a meta-analysis. Clinical psychology review, 30, 25-36.

Ebmeier, K. P., Donaghey, C., \& Steele, J. D. (2006). Recent developments and current controversies in depression. Lancet, 367, 153-67.

20 Fann, J. R., Berry, D. L., Wolpin, S., Austin-Seymour, M., Bush, N., Halpenny, B., 21 Lober, W. B., \& McCorkle, R. (2009). Depression screening using the Patient 22 Health Questionnaire-9 administered on a touch screen computer.

23 Psycho-oncology, 18, 14-22. 
1 Farchione, T. J., Fairholme, C. P., Ellard, K. K., Boisseau, C. L., Thompson-Hollands,

5 Fosha, D. (2000). The transforming power of affect : a model for accelerated change.

7 Frederick, R. J. (2009). Living like you mean it: Use the wisdom and power of your

9 Graham, J. W. (2009). Missing data analysis: making it work in the real world. J., Carl, J. R., Gallagher, M. W., \& Barlow, D. H. (2012). Unified protocol for transdiagnostic treatment of emotional disorders: a randomized controlled trial. Behavior therapy, 43, 666-78. New York: BasicBooks. emotions to get the life you really want. San Francisco: Jossey-Bass. Annual review of psychology, 60, 549-76.

Gueorguieva, R., \& Krystal, J. H. (2004). Move over ANOVA: progress in analyzing repeated-measures data and its reflection in papers published in the Archives of General Psychiatry. Archives of general psychiatry, 61, 310-7.

Guy, W. (1976). Clinical global impressions. ECDEU assessment manual for psychopharmacology. Rockville: NIMH.

Hedman, E., Ljótsson, B., \& Lindefors, N. (2012). Cognitive behavior therapy via the Internet: a systematic review of applications, clinical efficacy and cost-effectiveness. Expert review of pharmacoeconomics \& outcomes research, 12, 745-64.

Hedman, E., Ljótsson, B., Rück, C., Bergström, J., Andersson, G., Kaldo, V., Jansson, L., Andersson, E., Blom, K., El Alaoui, S., Falk, L., Ivarsson, J., Nasri, B., Rydh, S., \& Lindefors, N. (2013). Effectiveness of Internet-based cognitive behaviour PeerJ reviewing PDF | (v2013:05:525:1:1:NEW 20 Jun 2013) 
1 Johansson, R., \& Andersson, G. (2012). Internet-based psychological treatments for depression. Expert review of neurotherapeutics, 12, 861-70.

3 Johansson, R., Ekbladh, S., Hebert, A., Lindström, M., Möller, S., Petitt, E., Poysti,

$4 \quad$ S., Larsson, M. H., Rousseau, A., Carlbring, P., Cuijpers, P., \& Andersson, G.

5 (2012). Psychodynamic guided self-help for adult depression through the

6 internet: a randomised controlled trial. PLoS ONE, 7, e38021.

7 Kessler, R. C., Berglund, P., Demler, O., Jin, R., Merikangas, K. R., \& Walters, E. E.

8 (2005). Lifetime prevalence and age-of-onset distributions of DSM-IV disorders

9 in the National Comorbidity Survey Replication. Archives of general psychiatry, $10 \quad 62,593-602$.

11 Kessler, R. C., Merikangas, K. R., \& Wang, P. S. (2007). Prevalence, comorbidity, 12 and service utilization for mood disorders in the United States at the beginning of 13 the twenty-first century. Annual review of clinical psychology, 3, 137-58.

14 Kroenke, K., Spitzer, R. L., \& Williams, J. B. (2001). The PHQ-9: validity of a brief 15 depression severity measure. Journal of general internal medicine, 16, 606-13.

16 Kroenke, K., Spitzer, R. L., Williams, J. B. W., \& Löwe, B. (2010). The Patient

17 Health Questionnaire Somatic, Anxiety, and Depressive Symptom Scales: a

18 systematic review. General hospital psychiatry, 32, 345-59.

19 Leichsenring, F., Salzer, S., Beutel, M. E., Herpertz, S., Hiller, W., Hoyer, J.,

20 Huesing, J., Joraschky, P., Nolting, B., Poehlmann, K., Ritter, V., Stangier, U.,

21 Strauss, B., Stuhldreher, N., Tefikow, S., Teismann, T., Willutzki, U., Wiltink,

22 J., \& Leibing, E. (2013). Psychodynamic Therapy and Cognitive-Behavioral

23 Therapy in Social Anxiety Disorder: A Multicenter Randomized Controlled

24 Trial. The American journal of psychiatry. 
1 Leichsenring, F., Salzer, S., Jaeger, U., Kächele, H., Kreische, R., Leweke, F., Rüger,

2 U., Winkelbach, C., \& Leibing, E. (2009). Short-term psychodynamic

3 psychotherapy and cognitive-behavioral therapy in generalized anxiety disorder:

4 a randomized, controlled trial. The American journal of psychiatry, 166, 875-81.

5 Lilja, J. L., Frodi-Lundgren, A., Hanse, J. J., Josefsson, T., Lundh, L.-G., Sköld, C.,

6 Hansen, E., \& Broberg, A. G. (2011). Five Facets Mindfulness Questionnaire -

7 reliability and factor structure: a Swedish version. Cognitive behaviour therapy,

$8 \quad 40,291-303$.

9 Malan, D. (1995). Individual psychotherapy and the science of psychodynamics (2nd

10 ed.). Oxford: Butterworth-Heinemann.

11 Mallinckrodt, C. H., Clark, W. S., \& David, S. R. (2001). Accounting for dropout bias

12 using mixed-effects models. Journal of biopharmaceutical statistics, 11, 9-21.

13 McCullough, L., Kuhn, N., Andrews, S., Kaplan, A., Wolf, J., \& Hurley, C. L. (2003).

14 Treating affect phobia: A manual for short-term dynamic psychotherapy. New

$15 \quad$ York: Guilford Press.

16 McEvoy, P., \& Nathan, P. (2007). Effectiveness of cognitive behavior therapy for

17 diagnostically heterogeneous groups: a benchmarking study. Journal of

18 consulting and clinical psychology, 75, 344-50.

19 McEvoy, P., Nathan, P., \& Norton, P. (2009). Efficacy of transdiagnostic treatments:

20 A review of published outcome studies and future research directions. Journal of

21 cognitive psychotherapy: An international quarterly, 23, 20-33.

22 Milrod, B., Leon, A. C., Busch, F., Rudden, M., Schwalberg, M., Clarkin, J.,

23 Aronson, A., Singer, M., Turchin, W., Klass, E. T., Graf, E., Teres, J. J., \&

24 Shear, M. K. (2007). A randomized controlled clinical trial of psychoanalytic PeerJ reviewing PDF | (v2013:05:525:1:1:NEW 20 Jun 2013) 
psychotherapy for panic disorder. The American journal of psychiatry, 164, 265-72.

3 Osimo, F., \& Stein, M. J. (2012). Theory and practice of experiential dynamic psychotherapy. London: Karnac.

5 Paxling, B., Lundgren, S., Norman, A., Almlöv, J., Carlbring, P., Cuijpers, P., \& 6 Andersson, G. (2013). Therapist behaviours in internet-delivered cognitive 7 behaviour therapy: analyses of e-mail correspondence in the treatment of 8 generalized anxiety disorder. Behavioural and cognitive psychotherapy, 41, $9 \quad 280-9$.

10 Röper, G., \& Rachman, S. (1976). Obsessional-compulsive checking: experimental replication and development. Behaviour research and therapy, 14, 25-32.

12 Salkovskis, P. M. (1985). Obsessional-compulsive problems: a cognitive-behavioural analysis. Behaviour research and therapy, 23, 571-83.

14 Schulz, K. F., Altman, D. G., \& Moher, D. (2010). CONSORT 2010 statement: updated guidelines for reporting parallel group randomised trials. PLoS medicine, 7, e1000251.

Shapiro, S., \& Wilk, M. (1965). An analysis of variance test for normality (complete samples). Biometrika, 52, 591-611.

19 Sheehan, D. V, Lecrubier, Y., Sheehan, K. H., Amorim, P., Janavs, J., Weiller, E., 20 Hergueta, T., Baker, R., \& Dunbar, G. C. (1998). The Mini-International 21 Neuropsychiatric Interview (M.I.N.I.): the development and validation of a 22 structured diagnostic psychiatric interview for DSM-IV and ICD-10. The 23 Journal of clinical psychiatry, 59 Suppl 2, 22-33;quiz 34-57. 
1 Smit, F., Cuijpers, P., Oostenbrink, J., Batelaan, N., De Graaf, R., \& Beekman, A. (2006). Costs of nine common mental disorders: implications for curative and preventive psychiatry. The journal of mental health policy and economics, 9, 193-200.

5 Spitzer, R. L., Kroenke, K., Williams, J. B. W., \& Löwe, B. (2006). A brief measure 6 for assessing generalized anxiety disorder: the GAD-7. Archives of internal $7 \quad$ medicine, $166,1092-7$.

8 Svartberg, M., Stiles, T. C., \& Seltzer, M. H. (2004). Randomized, controlled trial of 9 the effectiveness of short-term dynamic psychotherapy and cognitive therapy for 10 cluster C personality disorders. The American journal of psychiatry, 161, 810-7.

11 Titov, N., Dear, B. F., Schwencke, G., Andrews, G., Johnston, L., Craske, M. G., \& 12 McEvoy, P. (2011). Transdiagnostic internet treatment for anxiety and 13 depression: a randomised controlled trial. Behaviour research and therapy, 49, $14 \quad 441-52$.

15 Town, J. M., Diener, M. J., Abbass, A., Leichsenring, F., Driessen, E., \& Rabung, S. 16 (2012). A meta-analysis of psychodynamic psychotherapy outcomes: Evaluating 17 the effects of research-specific procedures. Psychotherapy (Chicago, Ill.), 49, $18 \quad 276-90$.

19 Verbeke, G., \& Molenberghs, G. (2000). Linear mixed models for longitudinal data. $20 \quad$ New York: Springer.

21 Winston, A., Laikin, M., Pollack, J., Samstag, L. W., McCullough, L., \& Muran, J. C. 22 (1994). Short-term psychotherapy of personality disorders. The American 23 journal of psychiatry, 151, 190-4. 


\section{Figures}

\section{Figure 1 - CONSORT flowchart}

\section{Figure 2 - Malan's two triangles}

5 The two triangles (Malan, 1995) represent what David Malan called "the universal

6 principle of psychodynamic psychotherapy”. That is, defenses (D) and anxieties (A)

7 can block the expression of true feelings (F). These patterns began with past persons

8 (P), are maintained with current persons (C), and are often enacted with the therapist 9 (T).

11 Figure 3 - Weekly PHQ-9 and GAD-7 scores

12 Weekly scores on the PHQ-9 and the GAD-7 for both groups. Vertical bars denote

13 95\% confidence intervals (CI). PHQ-9: 9-item Patient Health Questionnaire

14 Depression Scale; GAD-7: 7-item Generalized Anxiety Disorder Scale. 


\section{Table $\mathbf{1}_{\text {(on next page) }}$}

Demographic description of the participants 


\section{Table 1}

Demographic description of the participants.

\begin{tabular}{|c|c|c|c|c|}
\hline & & Treatment group & Control group & Total \\
\hline \multirow[t]{2}{*}{ Gender } & Male $\underline{\underline{\underline{E}}}$ & $8(16 \%)$ & $10(20 \%)$ & $18(18 \%)$ \\
\hline & 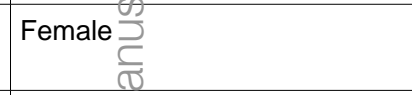 & $42(84 \%)$ & $40(80 \%)$ & $82(82 \%)$ \\
\hline \multirow[t]{2}{*}{ Age } & $\begin{array}{r}\text { Mean ( } \overline{(\underline{S D})} \\
\overline{0}\end{array}$ & $43.1(13.9)$ & $46.6(12.1)$ & $44.9(13.1)$ \\
\hline & $\operatorname{Min}-\operatorname{Max}$ & $19-72$ & $23-77$ & $19-77$ \\
\hline \multirow[t]{2}{*}{ Marital status } & $\begin{array}{c}\text { Married के co-habiting } \\
\simeq\end{array}$ & $31(62 \%)$ & $36(72 \%)$ & 67 (67\%) \\
\hline & Other & $19(38 \%)$ & $14(28 \%)$ & $33(33 \%)$ \\
\hline \multirow[t]{2}{*}{ Educational level } & $\begin{array}{l}\text { Colleg } \\
\text { years }\end{array}$ & $27(54 \%)$ & $29(58 \%)$ & $56(56 \%)$ \\
\hline & Other & $23(46 \%)$ & $21(42 \%)$ & 44 (44\%) \\
\hline \multirow[t]{2}{*}{ Employment status } & Employed or student & $41(82 \%)$ & $33(66 \%)$ & $74(74 \%)$ \\
\hline & Other & $9(18 \%)$ & 17 (34\%) & $26(26 \%)$ \\
\hline \multirow[t]{3}{*}{ Psychological treatment } & No experience & $15(30 \%)$ & $16(32 \%)$ & $31(31 \%)$ \\
\hline & Prior experience & $35(70 \%)$ & $31(62 \%)$ & $66(66 \%)$ \\
\hline & Ongoing & $0(0 \%)$ & $3(6 \%)$ & $3(3 \%)$ \\
\hline \multirow[t]{2}{*}{ Pharmacological treatment } & No experience & 27 (54\%) & $22(44 \%)$ & 49 (49\%) \\
\hline & Prior experience & $14(28 \%)$ & $12(24 \%)$ & $26(26 \%)$ \\
\hline
\end{tabular}




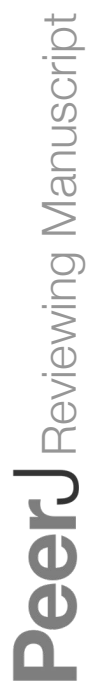




\section{Table $2_{\text {(on next page) }}$}

Means, SDs and effect sizes (Cohen’s d) for measures of depression and anxiety.

Abbreviations: PHQ-9: 9-item Patient Health Questionnaire Depression Scale; GAD-7: 7-item Generalized Anxiety Disorder Scale.

Note : The confidence intervals were calculated using the standard error and an alpha level of 0.05. A confidence interval that do not overlap zero indicates a significance of $p<.05$. $p$ values are given for linear mixed models using data from pre-treatment and post-treatment and all individuals ( $N=100$ ). The $p$ value associated with the main effect of group denotes significance of average difference between groups at the pre-treatment assessment. The $p$ value associated with the effect of time denotes the significance of average change over all assessment periods across treatment. The $p$ value associated with the effect of $\mathrm{G} \times \mathrm{T}$ (group $\times$ time) denotes significance of difference between the treatment group and the control group in change over all assessment periods. Effect sizes are calculated as standardized mean differences. 


\section{Table 2}

Means, SDs and effect sizes (Cohen's d) for measures of depression and anxiety.

\begin{tabular}{|c|c|c|c|c|c|c|c|c|}
\hline \multirow[b]{2}{*}{ Measure and group } & \multicolumn{3}{|c|}{ Mean (SD) } & \multicolumn{3}{|c|}{ Effect size Cohen's d $(95 \% \mathrm{Cl})$} & \multicolumn{2}{|c|}{ Linear mixed models } \\
\hline & $\begin{array}{c}\text { Pre-黑eatment } \\
\frac{D}{D} \\
\frac{\mathscr{D}}{D}\end{array}$ & Post-treatment & $\begin{array}{l}\text { 7-month } \\
\text { follow-up }\end{array}$ & $\begin{array}{c}\text { Between-group, } \\
\text { post-treatment }\end{array}$ & $\begin{array}{l}\text { Within-group } \\
\text { pre-post-treatment }\end{array}$ & $\begin{array}{l}\text { Within-group } \\
\text { pre-7-month follow-up }\end{array}$ & Effect & $p$ \\
\hline \multicolumn{9}{|c|}{ 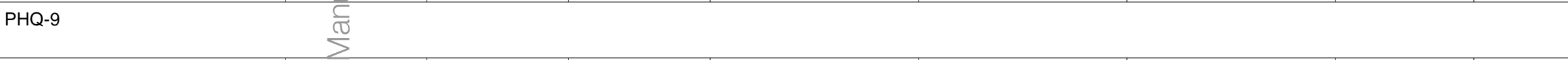 } \\
\hline Treatment group $(n=50)$ & $\stackrel{13.90(3.6)}{=}$ & $6.32(4.2)$ & $5.55(3.5)$ & $0.77(0.37-1.18)$ & $1.93(1.31-2.55)$ & $2.43(1.72-3.14)$ & Group & .89 \\
\hline Depression subgroup $(n=28)$ & $1532(3.3)$ & $5.89(2.8)$ & $5.96(3.5)$ & $0.95(0.40-1.50)$ & $3.10(1.87-4.32)$ & $2.82(1.78-3.87)$ & Time & $<.001$ \\
\hline Anxiety subgroup $(n=22)$ & 12.09 (3.3) & $6.86(5.5)$ & $5.00(3.4)$ & $0.55(-0.06-1.16)$ & $1.12(0.49-1.75)$ & $2.17(1.11-3.24)$ & $G \times T$ & $<.001$ \\
\hline Control group $(n=50)$ & $106(4.7)$ & $10.26(5.9)$ & & & $0.69(0.40-0.97)$ & & & \\
\hline Depression subgroup $(n=29)$ & $1007(4.4)$ & $10.59(6.4)$ & & & $0.79(0.37-1.22)$ & & & \\
\hline Anxiety subgroup $(n=21)$ & $12.43(4.7)$ & $9.81(5.2)$ & & & $0.53(0.20-0.85)$ & & & \\
\hline \multicolumn{9}{|l|}{ GAD-7 } \\
\hline Treatment group $(n=50)$ & $11.46(4.0)$ & $6.12(4.5)$ & $5.34(4.1)$ & $0.48(0.08-0.87)$ & $1.25(0.79-1.71)$ & $1.51(0.97-2.06)$ & Group & .85 \\
\hline Depression subgroup $(n=28)$ & $10.86(4.1)$ & $5.46(3.9)$ & $5.19(4.1)$ & $0.56(0.03-1.09)$ & $1.35(0.75-1.95)$ & $1.43(0.73-2.10)$ & Time & $<.001$ \\
\hline Anxiety subgroup ( $n=22)$ & $12.23(3.8)$ & $6.95(5.3)$ & $5.55(4.2)$ & $0.39(-0.21-0.99)$ & $1.15(0.44-1.86)$ & $1.62(0.72-2.52)$ & $G \times T$ & $<.01$ \\
\hline Control group $(n=50)$ & $12.26(4.2)$ & $8.40(5.0)$ & & & $0.82(0.51-1.13)$ & & & \\
\hline Depression subgroup $(n=29)$ & $11.97(5.0)$ & $8.03(5.3)$ & & & $0.76(0.39-1.13)$ & & & \\
\hline Anxiety subgroup $(n=21)$ & $12.67(2.8)$ & $8.90(4.7)$ & & & $0.93(0.36-1.50)$ & & & \\
\hline
\end{tabular}


Abbreviations: PHQ-9: 9-item Patient Health Questionnaire Depression Scale; GAD-7: 7-item Generalized Anxiety Disorder Scale.

Note: The confidence intervals were calculated using the standard error and an alpha level of 0.05 . A confidence interval that do not overlap zero indicates a significance of $p<.05$. $p$ values are given for linear mixed models using data from pre-treatment and post-treatment and all individuals $(N=100)$. The $p$ value associated with the main effect of group denotes significance of average difference between groups at the pre-treatment assessment. The $p$ value associated with the effect of time denotes the significance of average change over all assessment periods across treatment. The $p$ value associated with the effegst of $\mathrm{G} \times \mathrm{T}$ (group $\times$ time) denotes significance of difference between the treatment group and the control group in change over all assessment perīiods. Effect sizes are calculated as standardized mean differences.

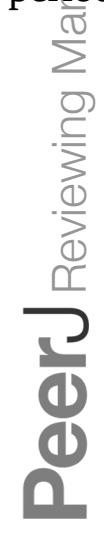




\title{
Table 3 (on next page)
}

Means, SDs and effect sizes (Cohen's d) for measures of emotional processing and mindfulness skills.

\begin{abstract}
Abbreviations: EPS-25: Emotional Processing Scale; FFMQ: Five Facets of Mindfulness Questionnaire.
\end{abstract}

Note : The confidence intervals were calculated using the standard error and an alpha level of 0.05 . A confidence interval that do not overlap zero indicates a significance of $p<.05$. $p$ values are given for linear mixed models using data from pre-treatment and post-treatment and all individuals ( $N=100)$. The $p$ value associated with the main effect of group denotes significance of average difference between groups at the pre-treatment assessment. The $p$ value associated with the effect of time denotes the significance of average change over all assessment periods across treatment. The $p$ value associated with the effect of $\mathrm{G} \times \mathrm{T}$ (group $\times$ time) denotes significance of difference between the treatment group and the control group in change over all assessment periods. Effect sizes are calculated as standardized mean differences. 


\section{Table 3}

Means, SDs and effect sizes (Cohen’s d) for measures of emotional processing and mindfulness skills.

\begin{tabular}{|c|c|c|c|c|c|c|c|c|}
\hline \multirow[b]{2}{*}{$\begin{array}{l}\text { Measure and } \\
\text { group }\end{array}$} & \multicolumn{3}{|c|}{ Mean (SD) } & \multicolumn{3}{|c|}{ Effect size Cohen's d $(95 \% \mathrm{Cl})$} & \multicolumn{2}{|c|}{ Linear mixed models } \\
\hline & Pre-treatment & 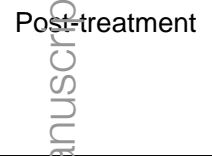 & $\begin{array}{l}\text { 7-month } \\
\text { follow-up }\end{array}$ & $\begin{array}{c}\text { Between-group, } \\
\text { post-treatment }\end{array}$ & $\begin{array}{l}\text { Within-group } \\
\text { pre-post-treatm } \\
\text { ent }\end{array}$ & Within-group pre-7-month follow-up & Effect & $p$ \\
\hline EPS-25 & & $\sum^{\infty}$ & & & & & Group & .50 \\
\hline $\begin{array}{l}\text { Treatment group } \\
(n=50)\end{array}$ & $5.00(1.03)$ & 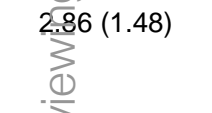 & $2.84(1.65)$ & $\begin{array}{c}0.82(0.41- \\
1.23)\end{array}$ & $\begin{array}{c}1.67(1.13- \\
2.21)\end{array}$ & $1.51(1.00-2.01)$ & Time & $<.001$ \\
\hline $\begin{array}{l}\text { Control group }(n= \\
50)\end{array}$ & $4.93(1.01)$ & $4.17(1.73)$ & & & $\begin{array}{c}0.50(0.22- \\
0.77)\end{array}$ & & $\mathrm{G} \times \mathrm{T}$ & $<.001$ \\
\hline FFMQ & & (d) & & & & & Group & .15 \\
\hline $\begin{array}{l}\text { Treatment group } \\
(n=50)\end{array}$ & $76.70(10.9)$ & (12.0) & $88.98(13.3)$ & $\begin{array}{c}0.65(0.25- \\
1.05)\end{array}$ & $\begin{array}{c}0.98(0.65- \\
1.31)\end{array}$ & $0.99(0.59-1.39)$ & Time & $<.001$ \\
\hline $\begin{array}{l}\text { Control group }(n= \\
50)\end{array}$ & $77.18(14.1)$ & $78.44(17.1)$ & & & $\begin{array}{c}0.08(-0.11- \\
0.27)\end{array}$ & & $\mathrm{G} \times \mathrm{T}$ & $<.001$ \\
\hline
\end{tabular}

Abbreviations: EPS-25: Emotional Processing Scale; FFMQ: Five Facets of Mindfulness Questionnaire.

Note: The confidence intervals were calculated using the standard error and an alpha level of 0.05 . A confidence interval that do not overlap zero indicates a significance of $p<.05$. $p$ values are given for linear mixed models using data from pre-treatment and post-treatment and all individuals $(N=100)$. The $p$ value associated with the main effect of group denotes significance of average difference between groups at the pre-treatment assessment. The $p$ value associated with the effect of time denotes the significance of average change over all assessment periods across treatment. The $p$ value associated with the effect of $\mathrm{G} \times \mathrm{T}$ (group $\times$ time) denotes significance of difference between the treatment group and the control group in change over all assessment periods. Effect sizes are calculated as standardized mean differences. 


\section{Table 4(on next page)}

Frequency data of DSM-IV diagnoses.

Note: The four participants with zero diagnoses listed at pre-treatment fulfilled DSM-IV criteria for depression and anxiety, not otherwise specified.

Abbreviations: DEP, GAD, SP, PD: Diagnoses of major depression, generalized anxiety disorder, social phobia and panic disorder. 


\section{Table 4}

Frequency data of DSM-IV diagnoses.

\begin{tabular}{|c|c|c|c|c|c|}
\hline \multirow[b]{2}{*}{ Diagnosis } & \multicolumn{3}{|c|}{ Treatment group } & \multicolumn{2}{|c|}{ Control group } \\
\hline & Pre-treatment & Post: $\frac{\text { treatment }}{\mathrm{U}}$ & 7-month follow-up & Pre-treatment & Post-treatment \\
\hline DEP & 35 (70\%) & $\begin{array}{l}5(10 \%) \\
\frac{\pi}{\sigma}\end{array}$ & $6(12 \%)$ & 37 (74\%) & $16(32 \%)$ \\
\hline GAD & $23(46 \%)$ & $\begin{array}{l}13(26 \%) \\
0\end{array}$ & $10(20 \%)$ & $26(52 \%)$ & $18(36 \%)$ \\
\hline SP & $19(38 \%)$ & $\left.\sum_{1}^{10} 20 \%\right)$ & $9(18 \%)$ & $17(34 \%)$ & $13(26 \%)$ \\
\hline PD & $11(22 \%)$ & $\begin{array}{l}5 \text { क्ष(10\%) } \\
\simeq\end{array}$ & $6(12 \%)$ & $9(18 \%)$ & $5(10 \%)$ \\
\hline $\begin{array}{l}\text { Number of } \\
\text { diagnoses }\end{array}$ & & (d) & & & \\
\hline 0 & $4(8 \%)$ & $28(56 \%)$ & $31(62 \%)$ & $0(0 \%)$ & $18(36 \%)$ \\
\hline 1 & $16(32 \%)$ & $13(26 \%)$ & $8(16 \%)$ & $23(46 \%)$ & $18(36 \%)$ \\
\hline 2 & $19(38 \%)$ & $7(14 \%)$ & $10(20 \%)$ & $16(32 \%)$ & $9(18 \%)$ \\
\hline 3 & $10(20 \%)$ & $2(4 \%)$ & $1(2 \%)$ & $10(20 \%)$ & $4(8 \%)$ \\
\hline 4 & $1(2 \%)$ & $0(0 \%)$ & $0(0 \%)$ & $1(2 \%)$ & $1(2 \%)$ \\
\hline $\begin{array}{l}\text { Total number of } \\
\text { diagnoses }\end{array}$ & 88 & 33 & 31 & 89 & 49 \\
\hline
\end{tabular}

Note: The four participants with zero diagnoses listed at pre-treatment fulfilled DSM-IV criteria for depression and anxiety, not otherwise specified. 
Abbreviations: DEP, GAD, SP, PD: Diagnoses of major depression, generalized anxiety disorder, social phobia and panic disorder.

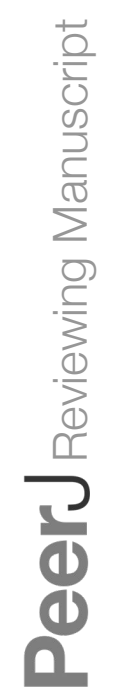


Figure 1

CONSORT flowchart

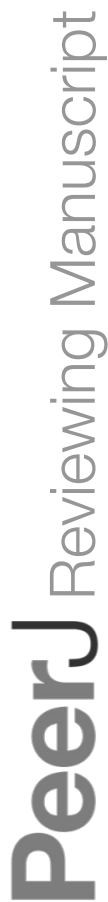

PeerJ reviewing PDF | (v2013:05:525:1:1:NEW 20 Jun 2013) 


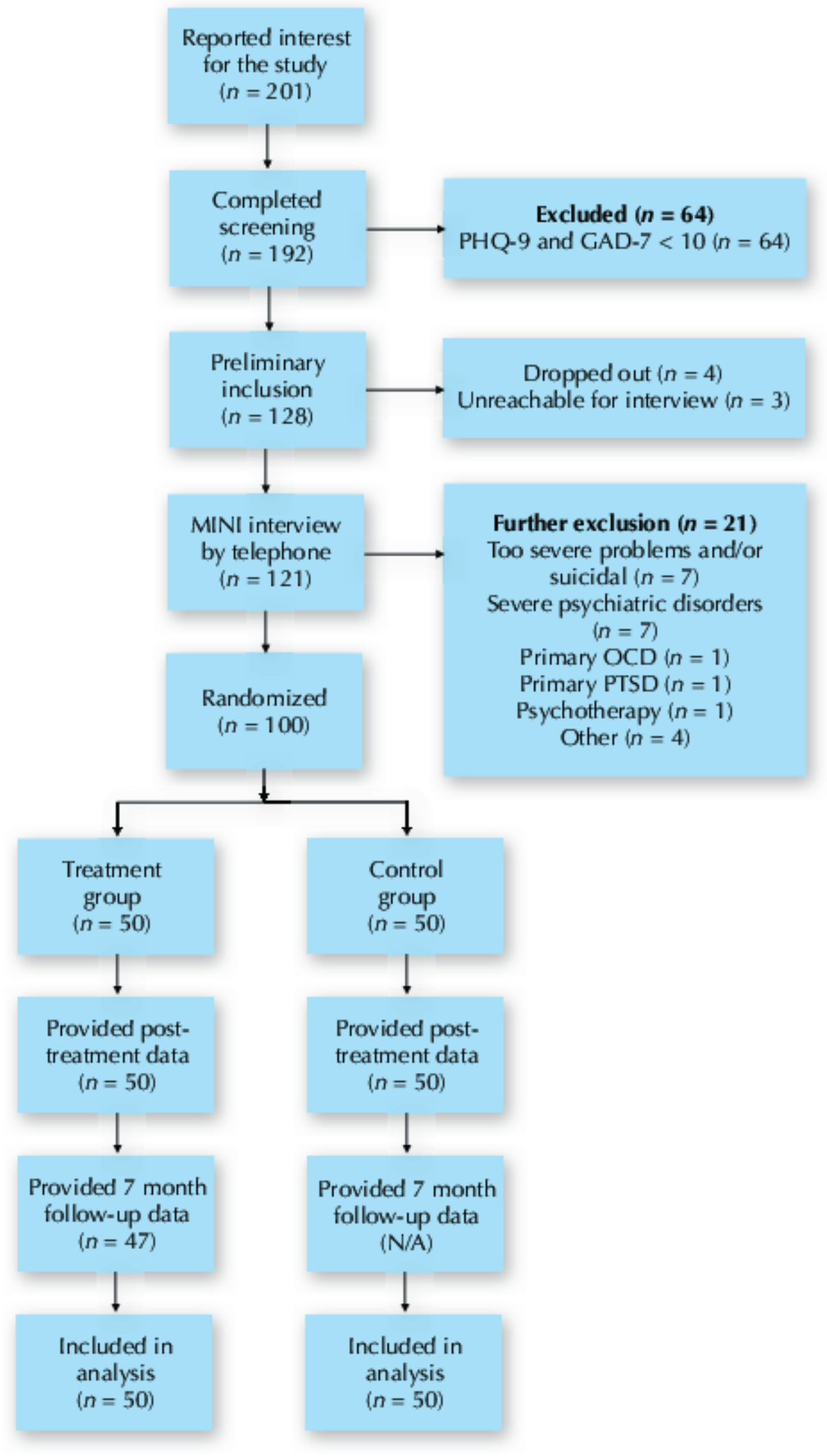




\section{Figure 2}

Malan's two triangles - the triangle of conflict and the triangle of person.

The two triangles (Malan, 1995) represent what David Malan called "the universal principle of psychodynamic psychotherapy”. That is, defenses (D) and anxieties (A) can block the expression of true feelings $(\mathrm{F})$. These patterns began with past persons $(\mathrm{P})$, are maintained with current persons $(\mathrm{C})$, and are often enacted with the therapist (T).
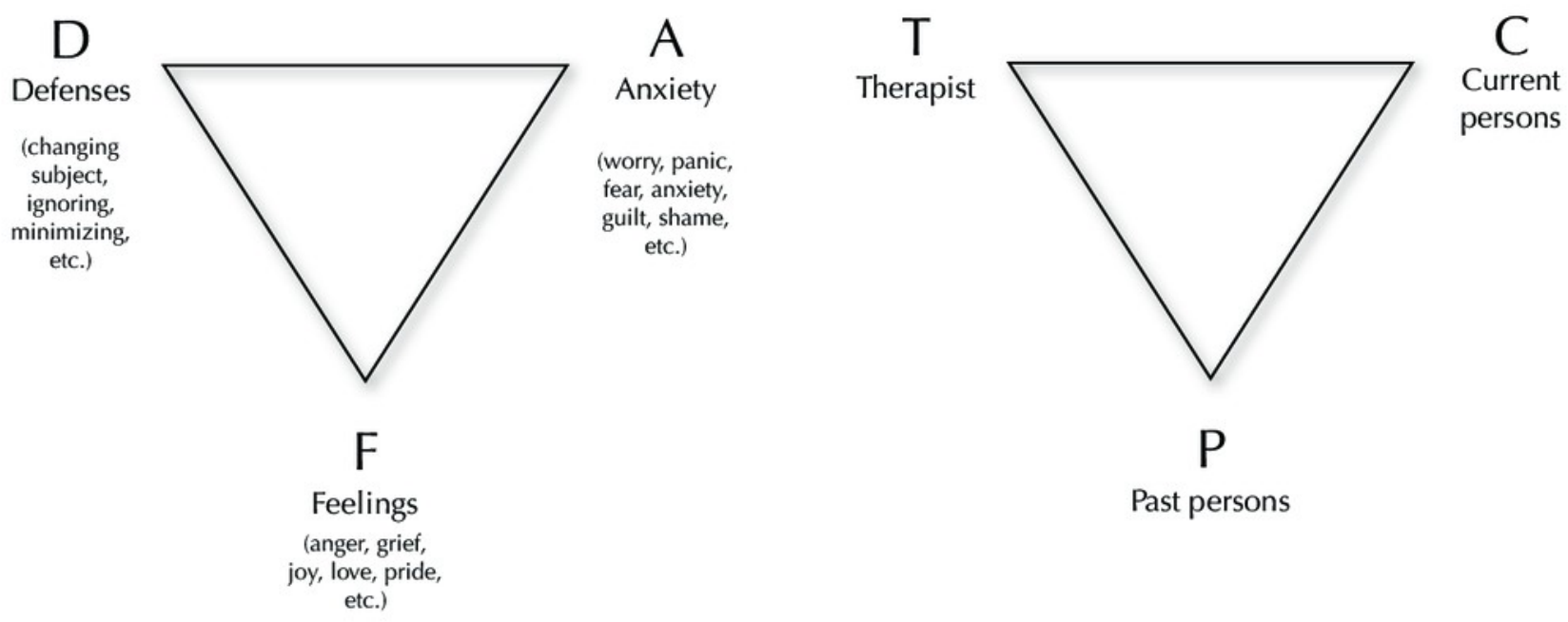

$P$

Past persons 


\section{Figure 3}

Weekly PHQ-9 and GAD-7 scores

Weekly scores on the PHQ-9 and the GAD-7 for both groups. Vertical bars denote 95\% confidence intervals (CI). PHQ-9: 9-item Patient Health Questionnaire Depression Scale; GAD-7: 7-item

Generalized Anxiety Disorder Scale.
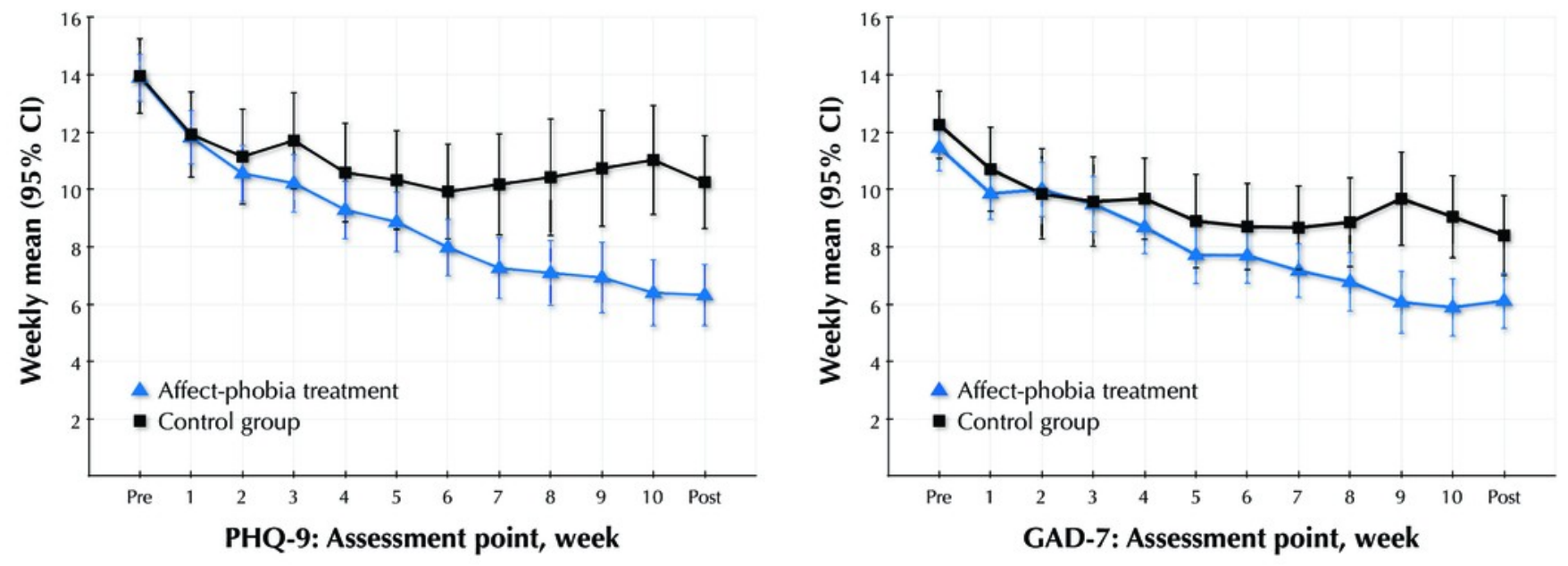